\title{
Installation and commissioning of the silicon pore optics coating facility for the
} ATHENA mission

Massahi, S.; Christensen, F. E.; Ferreira, D. D. MDella Monica F; Jafari, A.; Svendsen, S.; Henriksen, P. L.; Shortt, B.; Ferreira, I.; Bavdaz, M.; Collon, M.

Total number of authors:

17

Published in:

Proceedings of SPIE 11119, Optics for EUV, X-Ray, and Gamma-Ray Astronomy IX

Link to article, DOI:

$10.1117 / 12.2528351$

Publication date:

2019

Document Version

Publisher's PDF, also known as Version of record

Link back to DTU Orbit

Citation (APA):

Massahi, S., Christensen, F. E., Ferreira, D. D. MD. M. F., Jafari, A., Svendsen, S., Henriksen, P. L., Shortt, B., Ferreira, I., Bavdaz, M., Collon, M., Landgraf, B., Girou, D. A., Langer, A., Schönberger, W., Wellner, T., Krumrey, M., \& Cibik, L. (2019). Installation and commissioning of the silicon pore optics coating facility for the ATHENA mission. In S. L. O'Dell, \& G. Pareschi (Eds.), Proceedings of SPIE 11119, Optics for EUV, X-Ray, and Gamma-Ray Astronomy IX (Vol. 11119). [111190F] SPIE - International Society for Optical Engineering. Proceedings of SPIE - The International Society for Optical Engineering https://doi.org/10.1117/12.2528351

\section{General rights}

Copyright and moral rights for the publications made accessible in the public portal are retained by the authors and/or other copyright owners and it is a condition of accessing publications that users recognise and abide by the legal requirements associated with these rights.

- Users may download and print one copy of any publication from the public portal for the purpose of private study or research.

- You may not further distribute the material or use it for any profit-making activity or commercial gain

- You may freely distribute the URL identifying the publication in the public portal 


\section{Installation and commissioning of the silicon pore optics coating facility for the ATHENA mission}

S. Massahi, F. E. Christensen, D. D. M. Ferreira, A. Jafari, S. Svendsen, et al.

S. Massahi, F. E. Christensen, D. D. M. Ferreira, A. Jafari, S. Svendsen, P. L. Henriksen, B. Shortt, I. Ferreira, M. Bavdaz, M. Collon, B. Landgraf, D. Girou, A. Langer, W. Schönberger, T. Wellner, M. Krumrey, L. Cibik, "Installation and commissioning of the silicon pore optics coating facility for the ATHENA mission," Proc. SPIE 11119, Optics for EUV, X-Ray, and Gamma-Ray Astronomy IX, 111190F (9 September 2019); doi: 10.1117/12.2528351

EviE Event: SPIE Optical Engineering + Applications, 2019, San Diego, California, United States 


\title{
Installation and commissioning of the Silicon Pore Optics coating facility for the ATHENA mission
}

\author{
S. Massahi ${ }^{1}$, F. E. Christensen ${ }^{1}$, D. D. M. Ferreira ${ }^{1}$, A. Jafari ${ }^{1}$, S. Svendsen ${ }^{1}$, P. L. Henriksen ${ }^{1}$, \\ B. Shortt ${ }^{2}$, I. Ferreira ${ }^{2}$, M. Bavdaz 2 , M. Collon ${ }^{3}$, B. Landgraf ${ }^{3}$, D. Girou ${ }^{3}$, A. Langer ${ }^{4}$, W. \\ Schönberger ${ }^{4}$, T. Wellner ${ }^{4}$, M. Krumrey ${ }^{5}$, L. Cibik ${ }^{5}$ \\ ${ }^{1}$ DTU, Technical University of Denmark, Elektrovej building 327, Kgs. Lyngby, Denmark \\ ${ }^{2}$ ESTEC, European Space Research and Technology Centre, Keplerlaan 1, AZ Noordwijk, The Netherlands \\ ${ }^{3}$ cosine, Oosteinde 36, 2361 HE Warmond, The Netherlands \\ ${ }^{4}$ Von Ardenne GmbH, Am Hahnweg 8, 01328 Dresden, Germany \\ ${ }^{5}$ Physikalisch-Technische Bundesanstalt (PTB), Abbestrasse 2-12, 10587 Berlin, Germany
}

Keywords: ATHENA coating facility, Silicon Pore Optics, DC Magnetron Sputtering, X-ray reflectometry, X-ray Optics, X-ray photoelectron spectroscopy

\begin{abstract}
We present the latest progress on the industrial scale coating facility for the Advanced Telescope for High-ENergy Astrophysics (ATHENA) mission. The facility has been successfully commissioned and tested, completing an important milestone in preparation of the Silicon Pore Optics (SPO) production capability. We qualified the coating facility by depositing iridium and boron carbide thin films in different configurations under various process conditions including pre-coating in-system plasma cleaning. The thin films were characterized with X-Ray Reflectometry (XRR) using laboratory X-ray sources $\mathrm{Cu} \mathrm{K-} \alpha$ at $8.048 \mathrm{keV}$ and PTB's four-crystal monochromator beamline at the synchrotron radiation facility BESSY II in the energy range from $3.6 \mathrm{keV}$ to $10.0 \mathrm{keV}$. Additional X-ray Photoelectron Spectroscopy (XPS) measurements were performed with Al K- $\alpha$ radiation to analyze the composition of the deposited thin films.
\end{abstract}

\section{INTRODUCTION}

The technology readiness of the X-ray optics for ATHENA advances swiftly ${ }^{1,2}$. With the foreseen mission launch date in 2031, an important milestone is approaching (official adoption of the mission by ESA), for which a demonstration of the technology readiness level 6 is required ${ }^{3}$. In this effort, an establishment of an industrialized mirror plate coating facility dedicated for ATHENA is $\mathrm{key}^{4}$. One of the major challenges in the establishment of the ATHENA coating facility was to transfer the coating quality (e.g. coating smoothness), from an R\&D level and at the same time up-scaling the throughput.

The thin film coatings selected for ATHENA have been under development for more than a decade and the current baseline for the ATHENA mission is an iridium layer with a low density material, such as boron carbide as a top layer ${ }^{5,6,7,8,9,10,11,12}$.

The timeline from market research to commissioning of the coating facility is summarized in Figure 1.

Further author information: (Send correspondence to S. Massahi)

S. Massahi: E-mail: sonmas@space.dtu.dk, Telephone: +4531241456

Optics for EUV, X-Ray, and Gamma-Ray Astronomy IX, edited by Stephen L. O'Dell, Giovanni Pareschi, Proc. of SPIE Vol. 11119, 111190F · C 2019 SPIE · CCC code: 0277-786X/19/\$21 · doi: 10.1117/12.2528351 
Timeline for establishing the coating facility for ATHENA

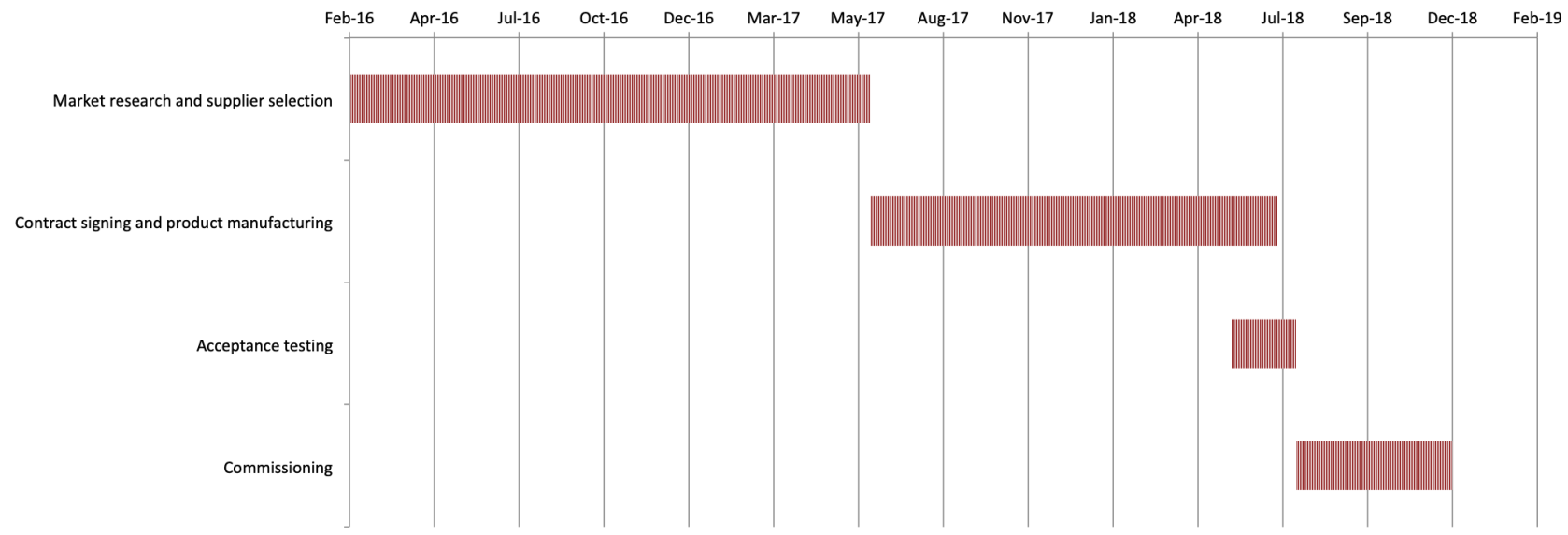

Figure 1: Gantt chart of the process from market research to commissioning of the dedicated coating facility for the ATHENA mission.

\section{ATHENA COATING FACILITY}

The coating facility dedicated for the ATHENA mission is located at cosine in The Netherlands (Figure 2) together with the stacking facility. The custom-made drum coater, BS1500S, has three process stations with currently two magnetrons and one inverse sputter etching unit accommodating three out of the four slots. This leaves one slot for a third magnetron making it possible to deposit tri-layer thin films (e.g. chromium, iridium and boron carbide).

The coating facility dedicated for ATHENA
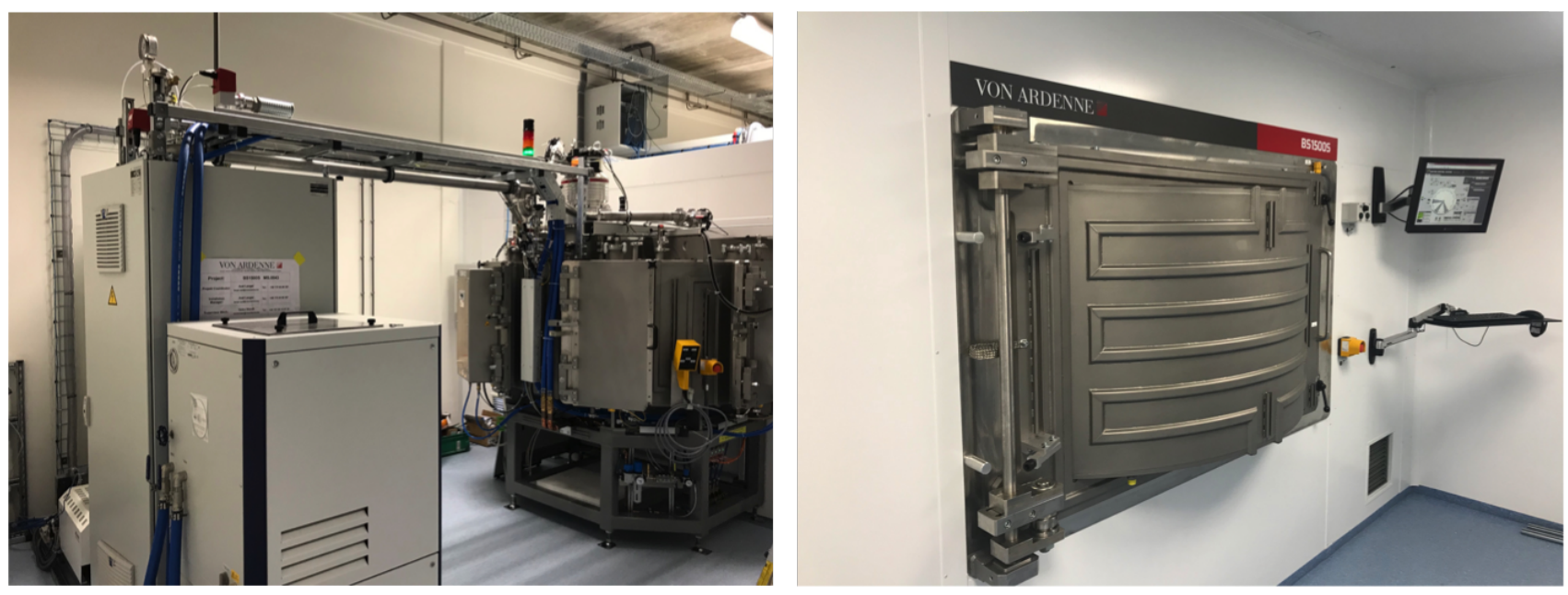

Figure 2: The fully operational ATHENA coating facility seen from the gray room (left) and the clean room (right). 


\subsection{Magnetrons}

A core component of the BS1500S is the planar Small Standard Magnetron (SSM) sputter source operated in DC mode. The SSMs are vertically arranged at the outer circumference of the process chamber (Figure 3) with the flanges of the magnetrons designed as doors for easy access to maintain or replace targets while ensuring low contamination. This improves the deposition process in terms of chamber preparation, pump-down time and maintenance.

The SSM source accommodates targets that are $600 \mathrm{~mm}$ long and $108 \mathrm{~mm}$ wide. The targets are bonded to a copper backing plate ensuring a smooth electrical conduction to the target as well as cooling of the target. To reduce the risk of the target cracking during high power loads, the targets are divided into tiles. An illustration of an SSM with target material is shown in Figure 3.

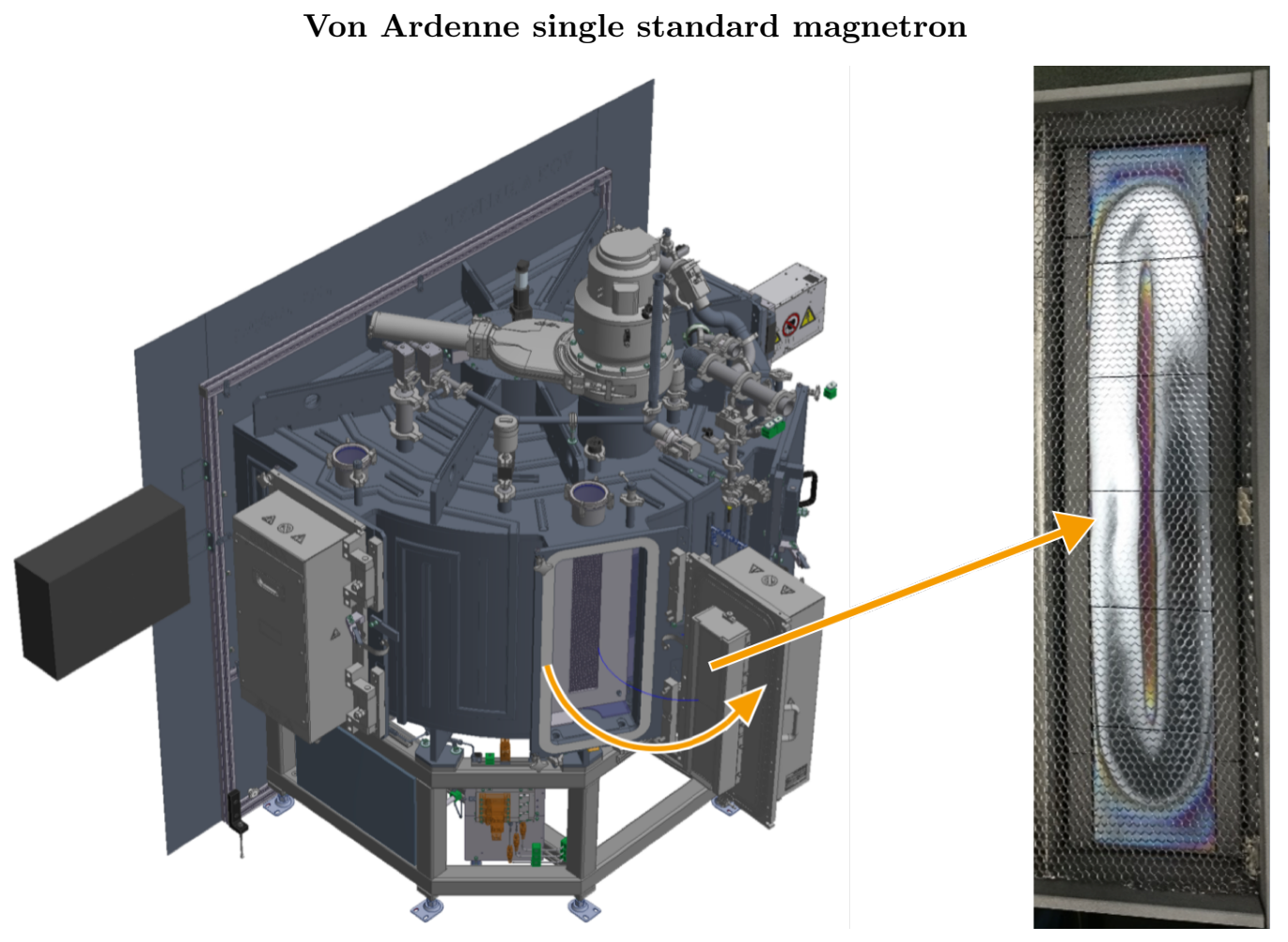

Figure 3: Frontside of a planar SSM with tiles of material. ${ }^{(}$Von Ardenne.

\subsection{The chamber integrated inverse sputter etcher}

Prior to the thin film deposition process, the mirror plates are exposed to the atmosphere which introduces surface contamination. For this reason, a surface cleaning/pre-treatment device, an Inverse Sputter Etcher (ISE) was integrated in the deposition chamber (Figure 4). The ISE enables surface cleaning prior to thin film deposition without breaking vacuum and exposing the surface to atmospheric contamination ensuring a thin film compatibility with the mirror plate chemical exposure procedure prior to the stacking process. 


\section{Inverse sputter etcher integrated in the BS1500S}
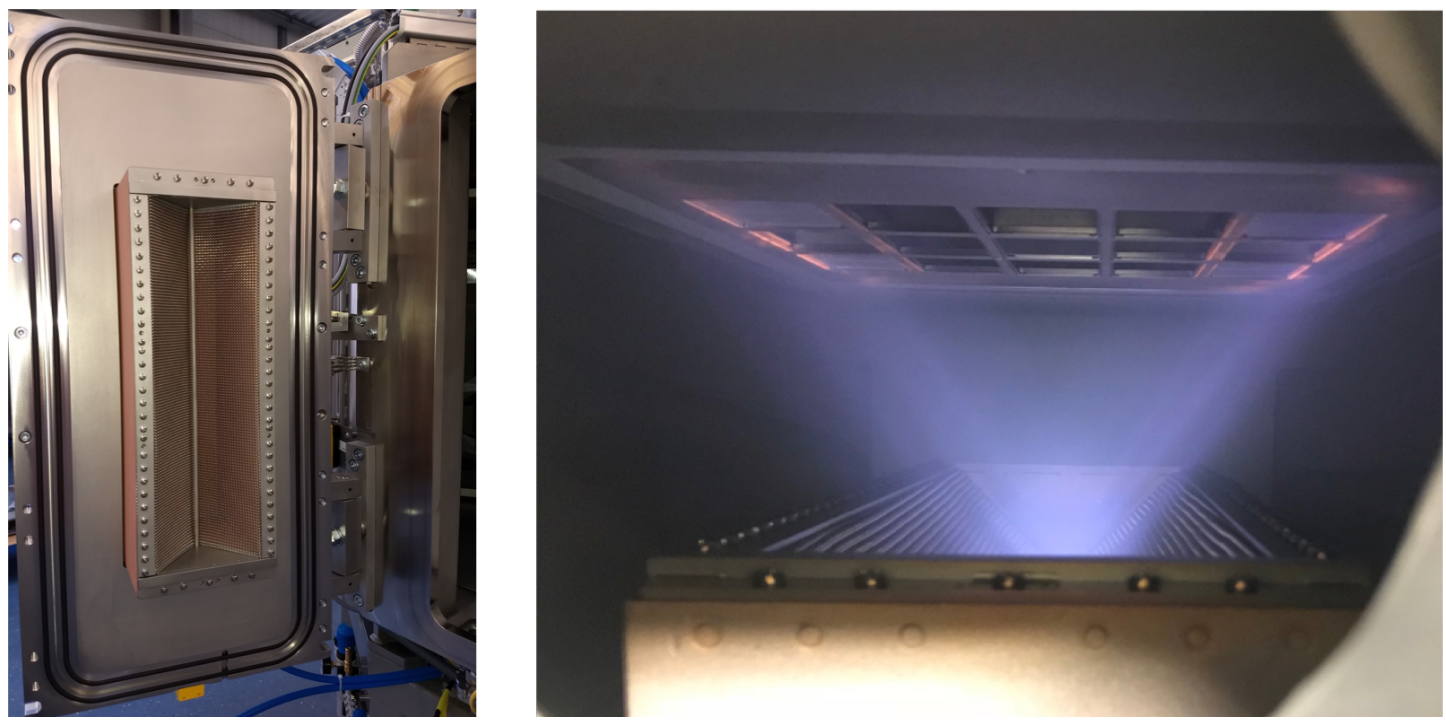

Figure 4: Left: Side view of the ISE. Right: Top view of a mirror plate plasma cleaning process performed in the BS1500S.

\subsection{Carrier design}

A carrier design was developed together with Von Ardenne to achieve a high throughput and the option of automating the mirror plate mounting. The carriers were constructed using two difference materials; the outer frame is made of aluminum and the inner frame is produced in stainless steel (Figure 5) which allows for maintenance of the carriers without damaging the high-precision features of the inner frames.

The mirror plate dimensions vary as a function of the radial position in the optics unit. Three different types of carriers were fabricated to demonstrate thin film deposition on inner, mid and outer radii mirror plates (Figure $6)$.

\section{Illustration of the carousel and the carriers}
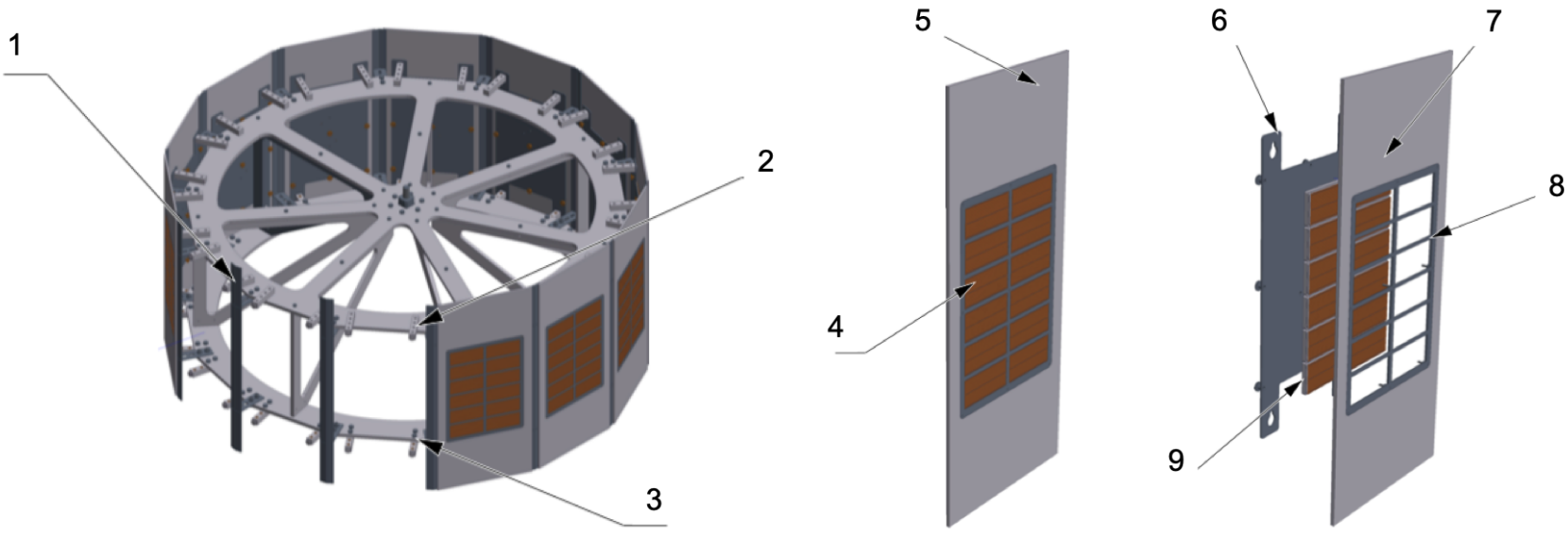

Figure 5: 1) Deposition guard, 2) Upper carrier holder, 3) Lower carrier holder, 4) Mirror plates, 5) Carrier prepared for mounting, 6) Back plate, 7) Outer frame, 8) Inner frame, 9) Back plates (mirror plate support). () Von Ardenne. 
Three different carrier designs with SPOs installed
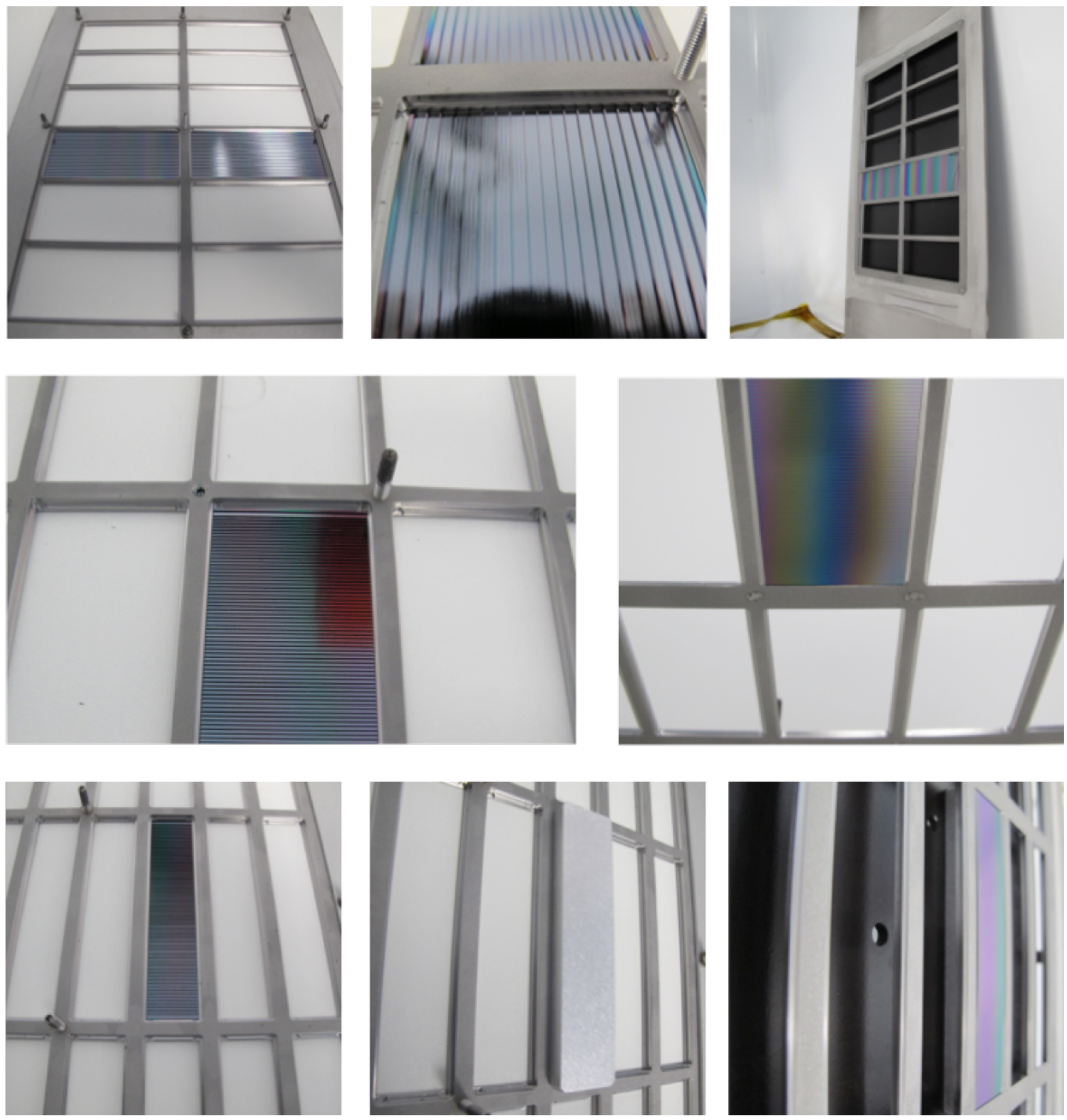

Figure 6: Top row: inner radius mirror plates. Center row: mid radius mirror plate. Bottom row: outer radius mirror plate.

\subsection{Acceptance testing}

Once the manufacturing of the drum coater was completed, the Factory Acceptance Testing (FAT) was conducted in Dresden which included testing a wide range of parameters such as pump-down time, plasma stability, target changing, safety procedures, thin film quality, etc.

The FAT experimental procedure was based on investigating the thin film parameter space within the current designs for the ATHENA mission. This included depositing several different thin films: a number of single- and bilayer films of iridium and boron carbide. This variety of thin films provided information about the surface and interface roughness, the deposition rate and the density.

The same experimental procedure performed at FAT was carried out at the Site Acceptance Testing (SAT). Through this, the reproducibility of the thin film quality before and after shipping the coating chamber was 
studied. The reproducibility of the iridium film is shown by comparing the reflectivity curves obtained with $8.048 \mathrm{keV}$ XRR (Figure 7).

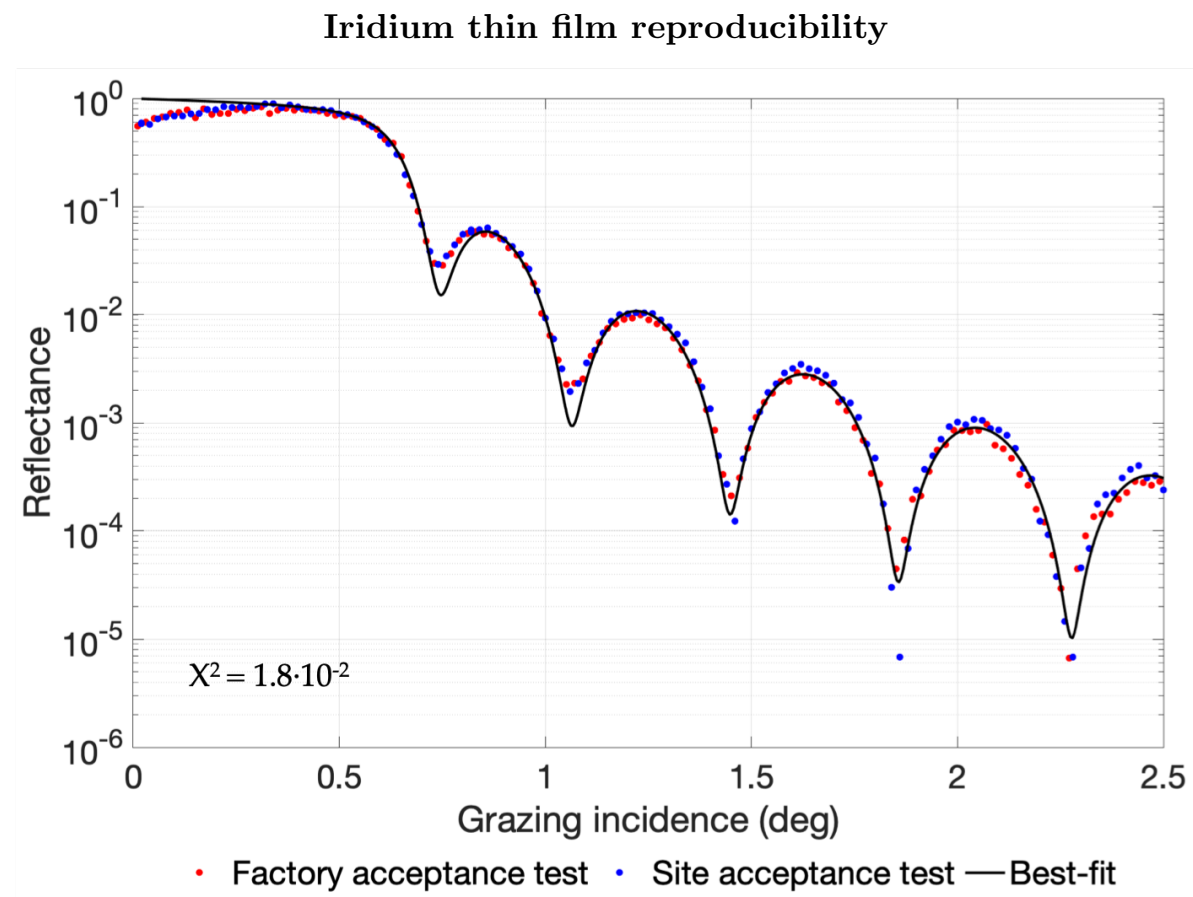

Figure 7: Comparison of reflectivity acquired with $8.048 \mathrm{keV}$ XRR of samples coated with a single layer of iridium at FAT and at SAT.

\section{COMMISSIONING}

In the commissioning phase several experimental procedures were established to investigate the thin film quality. These experiments were carefully designed to test the performance of the drum coater as well as the thin films produced in the machine.

The parameter settings used to perform the experiments in the commissioning phase are given in Table 1. The parameters are based on the values applied to the DTU Space DC magnetron deposition process. The sample rotation velocity given in Table 1 were based on calibration measurements from the chamber acceptance testing with an aimed layer thickness of $10.0 \mathrm{~nm}$ for both types of materials.

Table 1: Deposition parameters of the sputtered iridium and boron carbide thin films.

\begin{tabular}{ccccccc}
\hline \hline Material & $\begin{array}{c}\text { Working } \\
\text { pressure } \\
(\mathrm{mbar})\end{array}$ & $\begin{array}{c}\text { Rotation } \\
\text { velocity } \\
(\mathrm{rpm})\end{array}$ & $\begin{array}{c}\text { Discharge } \\
\text { power } \\
(\mathrm{W})\end{array}$ & $\begin{array}{c}\text { Discharge } \\
\text { voltage } \\
(\mathrm{V})\end{array}$ & $\begin{array}{c}\text { Discharge } \\
\text { current } \\
(\mathrm{A})\end{array}$ & $\begin{array}{c}\text { Power } \\
\text { density } \\
\left(\mathrm{W} / \mathrm{cm}^{2}\right)\end{array}$ \\
\hline Iridium & $3.5 \cdot 10^{-3}$ & 0.128 & 1860 & 600 & 3.10 & 3.10 \\
Boron carbide & $3.5 \cdot 10^{-3}$ & 0.032 & 3200 & 705 & 4.54 & 5.17 \\
\hline \hline
\end{tabular}




\subsection{Coating uniformity study}

The coating uniformity is a key parameter in the foreseen calibration effort for ATHENA. For this reason, it was important during the commissioning phase to map the coating uniformity as a function of mirror position ${ }^{13}$.

The experiment was designed to map the coating uniformity across a carrier plate in both the horizontal and vertical direction. This was done by mounting silicon samples with a center-to-center distance in the vertical and horizontal direction of $75 \mathrm{~mm}$ and $90 \mathrm{~mm}$, respectively (illustrated in Figure 8, left and center) and depositing $10 \mathrm{~nm}$ of iridium on top. The coating footprint on a carrier is presented in Figure 8 (right) where the edge effect of the magnetic racetrack is visible.

\section{Coating uniformity map of single layer iridium films}
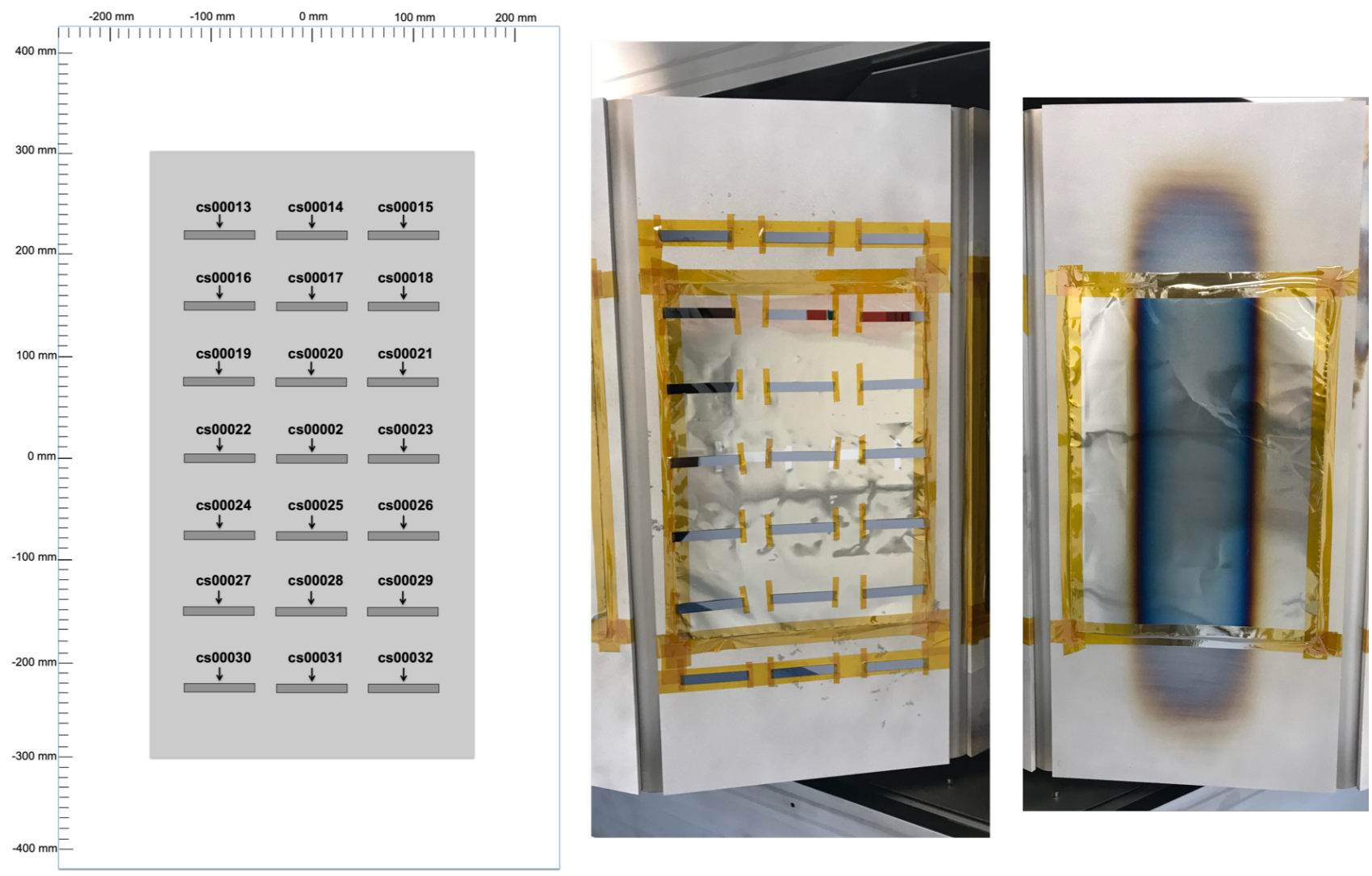

Figure 8: Left: Illustration of the mounted mirror substrates across the carrier. Center: Actual setup with kapton tape. Right: Coating footprint on a carrier where the edges are circular due to the static magnetic field.

The samples were characterized with $8.048 \mathrm{keV}$ XRR at $0-3$ deg grazing incidence. Based on the best-fit thickness parameters of the iridium films, a linearly interpolated coating uniformity map was created. This is shown in Figure 9 where a coating uniformity better than $5 \%$ along the $300 \mathrm{~mm}$ is achieved. To even out the coating uniformity in the vertical direction, future work could involve designing, manufacturing, installing and testing of a mask with the purpose of decreasing the flux of the sputtered particles from the center of the target. 


\section{Coating uniformity map of single layer iridium films}

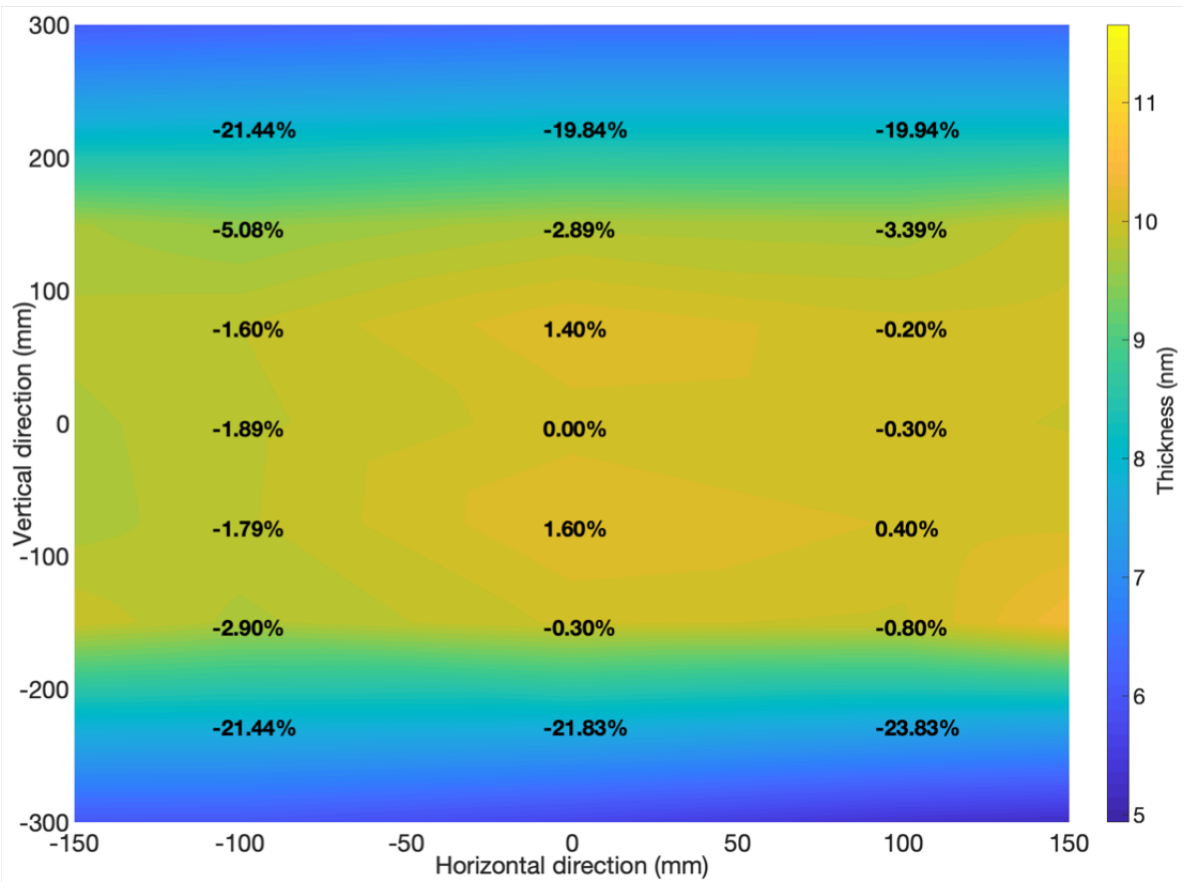

Figure 9: Linear interpolation of the relative iridium film thickness deviation with respect to the iridium film thickness of the centrally placed sample cs00002.

\subsection{Collimation study}

The R\&D magnetron deposition process includes a so-called honeycomb mesh in the path between the target and the substrate with the purpose of collimating the sputtered flux of atoms ${ }^{14}$. For this reason the BS1500S was fabricated with the option to install a honeycomb mesh and the purpose of this experiment was to evaluate to which degree the honeycomb mesh reduced the surface roughness of the sputtered films. Furthermore, the coating deposition rate, coating surface roughness and coating uniformity of iridium and boron carbide single layer films were investigated by including and excluding the honeycomb mesh.

A significant increase in Dynamic Deposition Rate (DDR) was observed for the samples deposited without the collimation mesh compared to the samples deposited with the collimation (Tables 2 and 3). The average DDR ratio between the iridium films deposited without the collimation mesh with respect to the iridium films deposited with the collimation was 2.49. The same tendency was observed for the boron carbide films, for which an increase in DDR of a factor 2.80 was observed (Table 3 ). This increase was not due to a change in sputter yield, however more sputtered atoms are blocked by the collimation mesh.

No significant difference was observed in best-fit surface roughnesses of the iridium films deposited excluding and including the honeycomb mesh. This is explained by the mass difference of the iridium atoms compared to the argon atoms. Despite the collisions of iridium atoms with argon atoms before landing on the substrate, the change in elastic scattering angle of the iridium atom is small due to iridium being much heavier than argon.

A large difference; a factor two to three, was observed between the best-fit surface roughnesses of the boron carbide films deposited without honeycomb mesh.

The coating uniformity of the iridium films deposited without collimation was significantly worsened in the 
vertical direction (from $3 \%$ including collimation to $>7 \%$ excluding collimation). This is illustrated in Figure 10. The same tendency was observed in the horizontal coating direction which is shown in the analysis of sample cs00037. Here, the reflectivity data was analyzed in two different grazing incidence angle intervals. The first interval was from $0-3$ deg grazing incidence where the best-fit thickness is an average value across the sample. The second interval is from $2.2-3.0 \mathrm{deg}$ which corresponds to the average thickness obtained across $\sim 3 \mathrm{~mm}$ in the measurement direction. The two different best-fit parameters show a discrepancy of $\sim 2 \mathrm{~nm}$ in thickness which is significant.

Collimation effect on deposition rate and coating uniformity
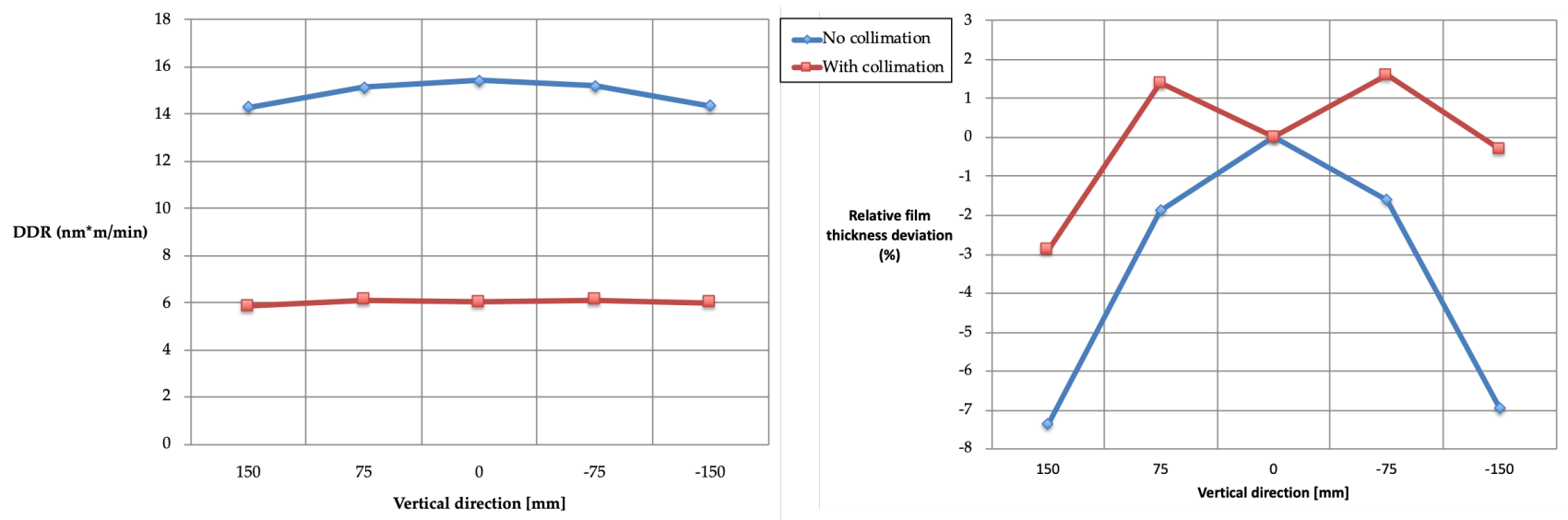

Figure 10: Left: Difference in DDR with and without honeycomb mesh. Right: Relative film thickness deviation with and without honeycomb mesh.

Table 2: Best-fit parameters of single layer iridium films deposited with (above dashed line) and without (below dashed line) honeycomb mesh. *Fit from $2.2-3.0 \mathrm{deg}$ (illuminating $3.13-2.29 \mathrm{~mm}$ of the sample)

\begin{tabular}{|c|c|c|c|c|}
\hline $\begin{array}{c}\text { Sample } \\
\text { ID }\end{array}$ & $\begin{array}{c}\text { Vertical distance } \\
\text { from position }(0.0) \\
(\mathrm{mm})\end{array}$ & $\begin{array}{c}\text { Fitted } \\
\text { thickness } \\
(\mathrm{nm})\end{array}$ & $\begin{array}{c}\text { Fitted } \\
\text { top roughness } \\
(\mathrm{nm})\end{array}$ & $\begin{array}{c}\text { Fitted } \\
\text { substrate roughness } \\
(\mathrm{nm})\end{array}$ \\
\hline $\operatorname{cs} 00017$ & 150 & 9.74 & 0.23 & 0.27 \\
\hline $\operatorname{cs} 00020$ & 75 & 10.17 & 0.26 & 0.34 \\
\hline $\operatorname{cs} 00002$ & 0 & 10.03 & 0.25 & 0.25 \\
\hline $\operatorname{cs} 00025$ & -75 & 10.19 & 0.26 & 0.29 \\
\hline cs00028 & -150 & 10.00 & 0.25 & 0.33 \\
\hline $\operatorname{cs} 00033$ & $-\overline{150}$ & $23.7 \overline{7}$ & 0.27 & $0 . \overline{36}$ \\
\hline $\operatorname{cs} 00034$ & 75 & 25.18 & 0.36 & 0.51 \\
\hline $\operatorname{cs} 00035$ & 0 & 25.66 & 0.28 & 0.47 \\
\hline $\operatorname{cs} 00036$ & -75 & 25.25 & 0.31 & 0.38 \\
\hline $\operatorname{cs} 00037$ & -150 & 23.88 & 0.30 & 0.34 \\
\hline $\operatorname{cs} 00037^{*}$ & -150 & $25.74^{*}$ & $0.44^{*}$ & $0.15^{*}$ \\
\hline
\end{tabular}


Table 3: Best-fit parameters of boron carbide thin films deposited with (cs00006) and without (cs00039) honeycomb mesh. The model is complex with several intermediate layers with different densities. *The modeling of all XRR data presented in this paper includes a fixed $1.00 \mathrm{~nm}$ silicon oxide layer on the silicon substrate surface.

\begin{tabular}{cccccc}
\hline \hline $\begin{array}{c}\text { Sample } \\
\text { ID }\end{array}$ & Layer & Composition & $\begin{array}{c}\text { Thickness } \\
(\mathrm{nm})\end{array}$ & $\begin{array}{c}\text { Density } \\
\left(\mathrm{g} / \mathrm{cm}^{3}\right)\end{array}$ & $\begin{array}{c}\text { Roughness } \\
(\mathrm{nm})\end{array}$ \\
\hline cs00006 & Top & $\mathrm{B}_{4} \mathrm{C}$ & 6.54 & 2.65 & 0.37 \\
& Intermediate 2 & $\mathrm{B}_{4} \mathrm{C}$ & 2.41 & 2.06 & 0.37 \\
& Intermediate 1 & $\mathrm{SiO}_{2}$ & $1.00^{*}$ & $2.65^{*}$ & 0.85 \\
& Substrate & $\mathrm{Si}$ & - & - & 0.85 \\
\hline cs00039 & Top & $\mathrm{B}_{4} \mathrm{C}$ & 4.25 & 2.69 & 0.99 \\
& Intermediate 3 & $\mathrm{B}_{4} \mathrm{C}$ & 19.70 & 2.48 & 0.99 \\
& Intermediate 2 & $\mathrm{B}_{4} \mathrm{C}$ & 1.03 & 2.03 & 0.99 \\
& Intermediate 1 & $\mathrm{SiO}_{2}$ & $1.00^{*}$ & $2.65^{*}$ & 0.85 \\
& Substrate & $\mathrm{Si}$ & - & - & 0.85 \\
\hline
\end{tabular}

\subsection{Target-to-substrate distance study}

The geometry of the coating chamber impacts the coating deposition rate, the coating roughness and the coating uniformity $^{15}$. In particular, the target-to-substrate distance (TSD) is a significant parameter for the coating quality and performance. It was decided to design and fabricate the BS1500S with three different TSDs: 105.0 $\mathrm{mm}, 125 \mathrm{~mm}$ and $150 \mathrm{~mm}$ (illustrated in Figure 11, right), based on the geometry of the deposition chamber at DTU Space for which the TSD is $155 \mathrm{~mm}$.

The BS1500S is equipped with magnetrons on the outside wall sputtering towards the center of the chamber. A sketch of the sputtering setup geometry in the BS1500S is presented in Figure 11 (left).
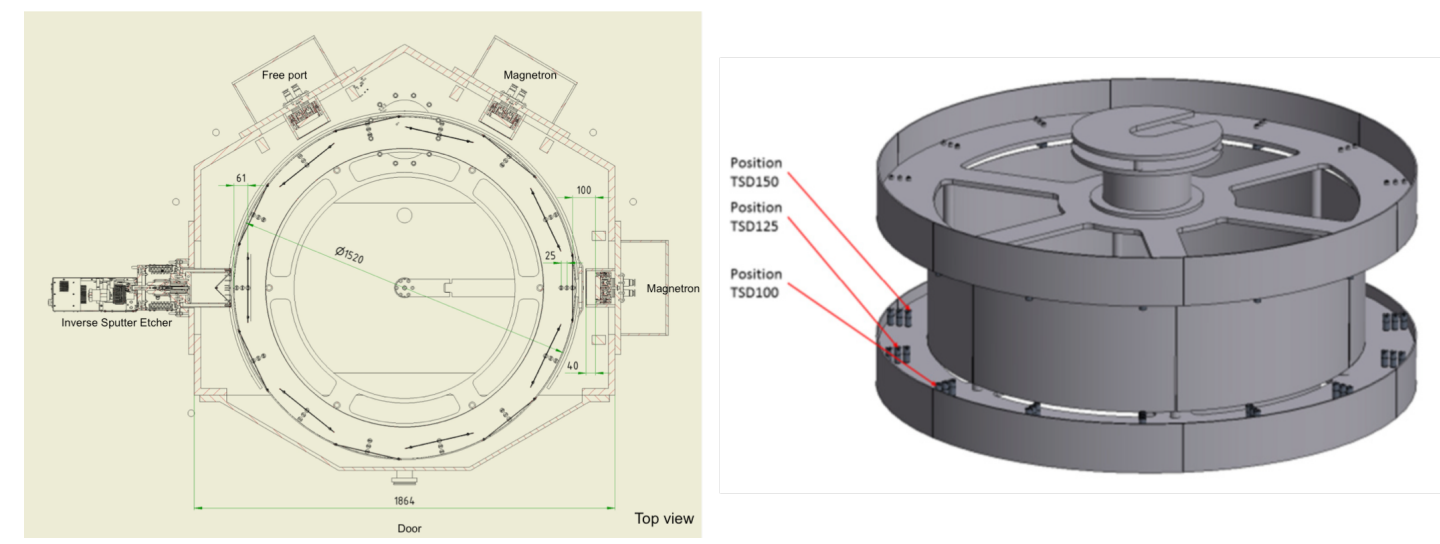

Figure 11: Technical sketch of the BS1500S. The diameter of the carousel is $1.4956 \mathrm{~m}$.) ${ }^{\circledR}$ Von Ardenne.

The best-fit parameters obtained with $8.048 \mathrm{keV}$ reflectivity data of the single layer iridium films are presented in Table 4. Based on the best-fit parameters of the iridium thickness, a comparison of the dynamic deposition rate as a function of the vertical position for the three different TSDs is presented in Figure 12 (left). The relative film thicknesses as a function of the vertical direction were significantly different for the three different 
TSDs (Figure 12, right) which is reflected in a worsening of the coating uniformity across the vertical direction of the carrier when increasing the TSD.

The surface roughness of the iridium films indicate no significant dependency on the TSD.

Table 4: Best-fit parameters of single layer iridium films deposited at different TSDs.

\begin{tabular}{|c|c|c|c|c|c|}
\hline $\begin{array}{c}\text { Sample } \\
\text { ID }\end{array}$ & $(\mathrm{mm})$ & $\begin{array}{c}\text { Vertical distance } \\
\text { from } \\
\text { position }(0.0) \\
(\mathrm{mm})\end{array}$ & $\begin{array}{c}\text { Fitted } \\
\text { thickness } \\
(\mathrm{nm})\end{array}$ & $\begin{array}{c}\text { Fitted } \\
\text { top } \\
\text { roughness } \\
(\mathrm{nm})\end{array}$ & $\begin{array}{c}\text { Fitted } \\
\text { substrate } \\
\text { roughness } \\
(\mathrm{nm})\end{array}$ \\
\hline $\operatorname{cs} 00017$ & 105.0 & 150 & 9.74 & 0.23 & 0.27 \\
\hline $\operatorname{cs} 00020$ & 105.0 & 75 & 10.17 & 0.26 & 0.34 \\
\hline $\operatorname{cs} 00002$ & 105.0 & 0 & 10.03 & 0.25 & 0.25 \\
\hline cs00025 & 105.0 & -75 & 10.19 & 0.26 & 0.29 \\
\hline $\operatorname{cs} 00028$ & 105.0 & -150 & 10.00 & 0.25 & 0.33 \\
\hline $\operatorname{cs} 00041$ & $\overline{126.5}$ & 150 & $\overline{9} . \overline{9}$ & 0.18 & 0.25 \\
\hline $\operatorname{cs} 00042$ & 126.5 & 75 & 10.39 & 0.19 & 0.23 \\
\hline $\operatorname{cs} 00043$ & 126.5 & 0 & 10.56 & 0.21 & 0.24 \\
\hline $\operatorname{cs} 00044$ & 126.5 & -75 & 10.55 & 0.20 & 0.24 \\
\hline $\operatorname{cs} 00045$ & 126.5 & -150 & 10.10 & 0.19 & 0.25 \\
\hline $\operatorname{cs} 00046$ & $15 \overline{5} . \overline{0}$ & 150 & $10.1 \overline{7}$ & $\overline{0} . \overline{2} 1$ & 0.26 \\
\hline $\operatorname{cs} 00047$ & 155.0 & 75 & 10.72 & 0.20 & 0.26 \\
\hline $\operatorname{cs} 00048$ & 155.0 & 0 & 10.86 & 0.22 & 0.25 \\
\hline $\operatorname{cs} 00049$ & 155.0 & -75 & 10.90 & 0.21 & 0.24 \\
\hline cs00050 & 155.0 & -150 & 10.24 & 0.23 & 0.28 \\
\hline
\end{tabular}

Target-to-substrate distance effect on iridium film thickness
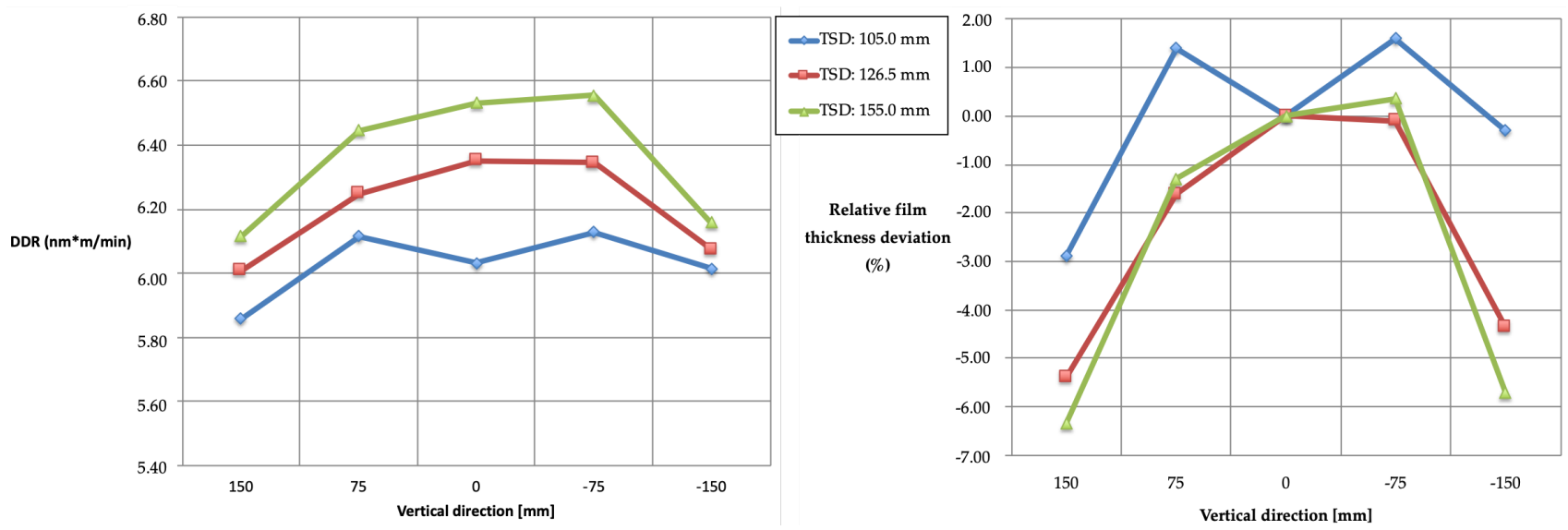

Figure 12: DDR and relative film thickness deviation as a function of vertical mirror plate position on the carrier for different TSDs. 


\subsection{Coating composition study of iridium/boron carbide bilayer film}

The purpose of this study was to investigate the composition of the sputtered iridium and boron carbide thin films. It was performed by depositing $10 \mathrm{~nm}$ of iridium with $8 \mathrm{~nm}$ of boron carbide onto silicon substrates. The composition of the thin films was examined through X-ray Photoelectron Spectroscopy (XPS) performed in a Thermo Scientific K- $\alpha$ system allowing for depth profiling analysis. The samples were probed with a monochromized beam (Al K- $\alpha: 1486.6 \mathrm{eV}$ ) with a spot size of approximately $400 \mu \mathrm{m}^{2}$.

Figure 13 (left) shows the atomic concentration as a function of etching time (related to the film depth profile). Here, the sample has been divided into five regions; the boron carbide film surface, the boron carbide film interior, the iridium film, the substrate surface and the silicon substrate. The film surface is dominated by oxygen and carbon which likely originate from the atmosphere in shape of hydrocarbons and water particles. This is supported by the binding energy peak positions presented in Figure 13 (right), for which carbon-oxygen bonds are detected. The boron carbide film interior contains a high amount of oxygen, hence there is no indication of boron-oxygen bonds (eg. $\mathrm{B}_{2} \mathrm{O}_{3}$ ) in the $\mathrm{B} 1 \mathrm{~s}$ spectrum. The oxygen is likely bound to other elements than boron. However, the peak binding energy located at $189.8 \mathrm{eV}$ may represent a chemical state of $\mathrm{B}_{x} \mathrm{C}_{y} \mathrm{O}_{z}$, which could explain the high percentage of oxygen in the film. A large concentration of the oxygen may be bound to the carbon as several oxide states were observed in the C1s spectrum.

The iridium film is very pure indicated by both illustrations in Figure 13. These results are similar to the results obtained for the iridium film deposited in the DTU Space coating facility. Underneath the iridium film in the transition to the substrate, a native silicon oxide layer is present.

\section{Thin film depth profile of the atomic concentration}

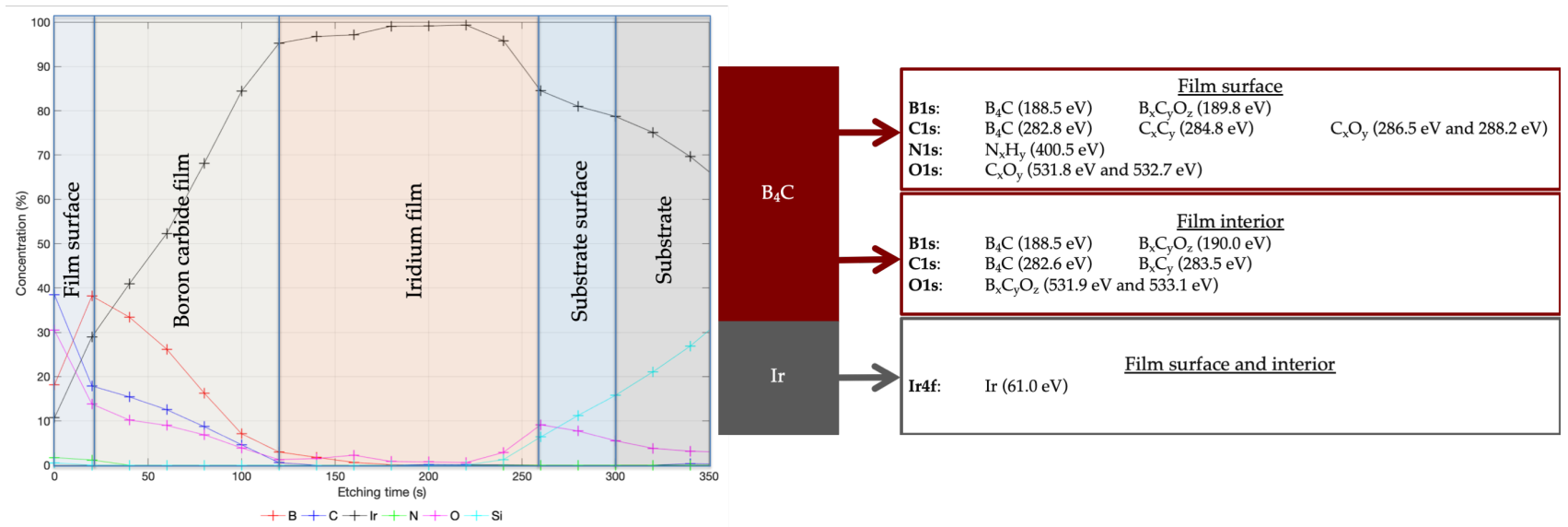

Figure 13: Atomic concentrations of boron carbide, iridium and silicon material content with the observed binding energies in the respective spectra. 


\subsection{Coating chemical exposure and time stability study}

The chemical exposure is part of the bonding activation of the mirror plates for ATHENA. It consists of a lift-off step where the photoresist is dissolved in dimethyl sulfoxide and an SC-1 removing organic material and etching oxide material. This is a harsh environment for thin film coatings in particular low density materials. Two mirror plates were coated with $10 \mathrm{~nm}$ of iridium and $8 \mathrm{~nm}$ of boron carbide on top and hereafter one of the samples was exposed to chemicals. Both samples were characterized from 3.6 to $10.0 \mathrm{keV}$ at a fixed grazing incidence of 0.6 degrees using PTB's four-crystal monochromator beamline at the synchrotron radiation facility BESSY II $^{16}$. Table 5 shows the best-fit parameters of the chemically untreated and treated sample. A slight discrepancy is observed between the thickness of the chemically untreated and treated boron carbide top-layer of $\sim 1.0 \mathrm{~nm}$. A plausible explanation for the thickness reduction is that the surface of the boron carbide oxidized when exposed to the atmosphere after deposition which is subsequently etched away in the SC-1 process ${ }^{17}$. This indicates that the surface oxidation is low for boron carbide films deposited in the ATHENA coating facility compared to boron carbide films deposited in the DTU Space coating facility inferring a higher compatibility of the boron carbide film deposited in the ATHENA coating facility with the chemical exposure processes ${ }^{18}$. With supporting data from the recently installed Low Energy X-ray Reflectometer we will obtain a deeper understanding of the film composition $^{19}$.

The time stability of the chemically untreated and treated samples is illustrated with reflectivity curves shown in Figure 14. The measurements were acquired at an interval of three months at the same beamline. No discrepancy is observed in the reflectivity of either of the two samples indicating a good time stability of the bilayer system. This is a preliminary result and future studies are planned to systematically investigate the time stability and chemical wear resistance of iridium/boron carbide bilayers.

Table 5: Best-fit parameters of chemical unexposed and exposed iridium/boron carbide bilayer films. ${ }^{*}$ The native oxide layer parameters are fixed values and not fitted parameters.

\begin{tabular}{cccccc}
\hline \hline Chemical exposure & Layer & Composition & $\begin{array}{c}\text { Thickness } \\
(\mathrm{nm})\end{array}$ & $\begin{array}{c}\text { Density } \\
\left(\mathrm{g} / \mathrm{cm}^{3}\right)\end{array}$ & $\begin{array}{c}\text { Roughness } \\
(\mathrm{nm})\end{array}$ \\
\hline \multirow{2}{*}{ None } & Top & $\mathrm{B}_{4} \mathrm{C}$ & 7.69 & 2.36 & 0.69 \\
& Intermediate 2 & $\mathrm{Ir}$ & 9.98 & - & 0.69 \\
& Intermediate 1 & $\mathrm{SiO}_{2}$ & $1.0^{*}$ & $2.65^{*}$ & 0.95 \\
& Substrate & $\mathrm{Si}$ & - & - & 0.95 \\
\hline Yes & Top & $\mathrm{B}_{4} \mathrm{C}$ & 6.75 & 2.28 & 0.73 \\
& Intermediate 2 & $\mathrm{Ir}$ & 9.98 & - & 0.73 \\
& Intermediate 1 & $\mathrm{SiO}_{2}$ & $1.0^{*}$ & $2.65^{*}$ & 0.88 \\
& Substrate & $\mathrm{Si}$ & - & - & 0.88 \\
\hline \hline
\end{tabular}

Proc. of SPIE Vol. 11119 111190F-13 


\section{Comparison of reflectivity curves shown for iridium/boron carbide bilayer films}
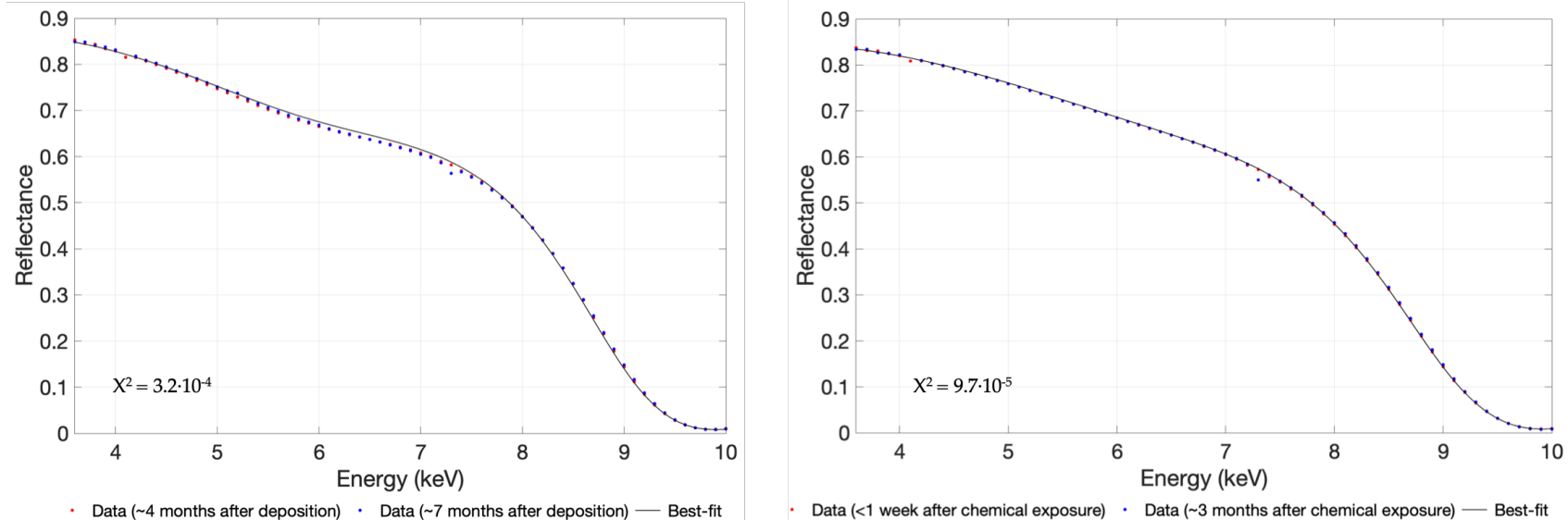

Figure 14: Best-fit reflectance curves of chemical unexposed (left) and exposed (right) iridium/boron carbide bilayer films. The time stability is indicated by overlapping data points.

\section{ESTIMATED MIRROR COATING THROUGHPUT FOR THE ATHENA FLIGHT PRODUCTION}

A rough estimate of the mirror plate coating production has been calculated based on the deposition parameters derived in the commissioning phase. The productivity estimate includes all aspects of the thin film deposition process from plate mounting in the deposition chamber to plate dismounting.

Approximately 150,000 mirror plates are required for the ATHENA flight optics. Considering that the mirror plates will be coated with either bilayers or optimized linear graded multilayers, the estimated coating production time is 332 days of continuous production. This does not include potential component failures in the coating facilities, which may induce long delays in the production time due to lead times. Furthermore, the demand of having operators working continuously is currently not planned for the ATHENA flight production.

\section{SUMMARY}

This work describes the establishment of a new coating facility comprising a DC magnetron sputtering machine compatible with the thin film coating requirements for the ATHENA mission. The BS1500S was designed, manufactured, tested and commissioned in collaboration between ESA, cosine, Von Ardenne and DTU Space. The new coating facility is suitable for the flight mirror coating phase provided a second coating machine is implemented.

Smooth iridium and boron carbide thin films were produced in the BS1500S and preliminary results indicate that the compositions of the thin films were stabile with time. This was confirmed by the XRR data acquired at PTB, BESSY II. The significance of including the honeycomb mesh in the deposition process was demonstrated. The surface roughness of the boron carbide films increased by a factor of $\sim 2$ without the honeycomb mesh. The best-fit surface roughnesses of the iridium films were low $<0.3 \mathrm{~nm}$ regardless of including or excluding the honeycomb mesh.

A coating uniformity study was carried out employing more than 30 witness samples. The purpose was to map the coating uniformity across the horizontal and vertical direction of the carrier to demonstrate a uniformity 
better than $5 \%$ across $300 \mathrm{~mm}$ in the vertical direction (ESA requirement). This requirement was fulfilled by using a target-to-substrate distance of $105 \mathrm{~mm}$ and the sufficiently tall magnetrons designed by Von Ardenne.

\section{ACKNOWLEDGEMENT}

This activity has been funded by the European Space Agency under contract AO/1-8285/15/NL/BW .

\section{REFERENCES}

1. M. Collon and et al., "Silicon pore optics mirror module production and testing," Space Telescopes and Instrumentation 2018: Ultraviolet To Gamma Ray 10699, p. 106990Y, 2018.

2. "Athena: The ESA Mission to explore the Hot and Energetic Universe." http://www. the-athena-x-ray-observatory.eu/images/AthenaPresentations/1903HEAD_Nandra_Athena.pdf.

3. "Technology readiness levels handbook for space applications." https://artes.esa.int/sites/default/ files/TRL_Handbook.pdf, 2008.

4. S. Massahi and et al., "Industrialization of the mirror plate coatings for the athena mission," Applications of Digital Image Processing 10399, p. 103991W, 2017.

5. D. Ferreira and et al., "Performance and stability of mirror coatings for the athena mission," Proceedings of SPIE 10699, p. 106993K, 2018.

6. A. Jakobsen and et al., "Preliminary coating design and coating developments for athena," Proceedings of SPIE 8147, p. 81470T, 2011.

7. D. Ferreira and et al., "Development and characterization of coatings on silicon pore optics substrates for the athena mission," Proceedings of SPIE 8443, p. 84435E, 2012.

8. D. Ferreira and et al., "Coating optimization for the athena+ mission," Proceedings of SPIE 8861, p. 886112, 2013.

9. D. Ferreira and et al., "X-ray mirror development and testing for the athena mission," Proceedings of SPIE 9905, p. 99055K, 2016.

10. D. Ferreira and et al., "Design, development, and performance of x-ray mirror coatings for the athena mission," Proceedings of SPIE, 2017.

11. S. Massahi and et al., "Development and production of a multilayer-coated x-ray reecting stack for the athena mission," Proceedings of SPIE 9905, p. 99055P, 2016.

12. S. Svendsen and et al., "Performance and stability of Ir/SiC X-ray mirror coatings for ATHENA," Proceedings of SPIE 11119, 2019.

13. N. Brejnholt, "Nustar calibration facility and multilayer reference database: Optic response model comparison to nustar on-ground calibration data," 2012.

14. A. Vickery and et al., "Collimated magnetron sputter deposition for mirror coatings," X-ray Optics and Instrumentation 2008, pp. 792540 (9 pp.), 792540 (9 pp.), 2008.

15. J. Broughton and et al., "Titanium sputter deposition at low pressures and long throw distances," Ieee Transactions on Semiconductor Manufacturing 9(1), pp. 122-127, 1996.

16. M. Krumrey and G. Ulm, "High-accuracy detector calibration at the ptb four-crystal monochromator beamline," Nuclear Instruments and Methods in Physics Research Section A-accelerators Spectrometers Detectors and Associated Equipment. 467, pp. 1175-1178, 2001. 
17. V. Pandit and et al., "Wet cleaning of cross-contamination of high-k dielectrics in plasma etch tool," Journal of the Electrochemical Society 153(11), pp. 017611JES, G970-G975, 2006.

18. S. Massahi, Industrialization of the mirror plate coatings for the ATHENA mission. PhD thesis, 2019.

19. P. L. Henriksen and et al., "LEXR: A low-energy X-ray reflectometer for characterization of ATHENA mirror coatings," Proceedings of SPIE 11119, 2019. 